\title{
]jfis
}

\section{A Matlab and Simulink Based Three-Phase Inverter Fault Diagnosis Method Using Three-Dimensional Features}

\author{
Muhammad Talha ${ }^{1}$, Furqan Asghar ${ }^{1}$, and Sung Ho Kim ${ }^{2}$ \\ ${ }^{1}$ School of Electronics and Information Engineering, Kunsan National University, Gunsan, Korea \\ ${ }^{2}$ School of IT, Information and Control Engineering, Kunsan National University, Gunsan, Korea
}

\begin{abstract}
Fault detection and diagnosis is a task to monitor the occurrence of faults and pinpoint the exact location of faults in the system. Fault detection and diagnosis is gaining importance in development of efficient, advanced and safe industrial systems. Three phase inverter is one of the most common and excessively used power electronic system in industries. A fault diagnosis system is essential for safe and efficient usage of these inverters. This paper presents a fault detection technique and fault classification algorithm. A new feature extraction approach is proposed by using three-phase load current in three-dimensional space and neural network is used to diagnose the fault. Neural network is responsible of pinpointing the fault location. Proposed method and experiment results are presented in detail.
\end{abstract}

Keywords: Three-phase inverter, Feature extraction, Fault detection, Fault diagnosis, Neural network, Matlab/Simulink

\section{Introduction}

In recent years, rapid industrial growth has increased the demand of high performance and efficient technology based systems. Continuous production is required to meet the market high demand. Therefore, any blockage or disturbance can cause million dollars lose to company. These issues have led the engineers to focus on the causes of these interruptions and carry out some research to minimize the probability of its occurrence [1].

Three-phase inverters are most common power converters in industry of all times. The is natural phenomenon in electronic systems. These inverter faults can be classified in to following [2].

1) $\mathrm{AC}$ line fault, single line to ground, line to line, missing line.

2) DC bus fault, earth fault, capacitor short circuit fault, voltage limiting transistor fault.

3) Gate switching faults.

4) DC link capacitor short-circuit fault.

5) Sensor faults, AC current sensor, DC bus voltage sensor, etc.

6) Faults in the control equipment. 


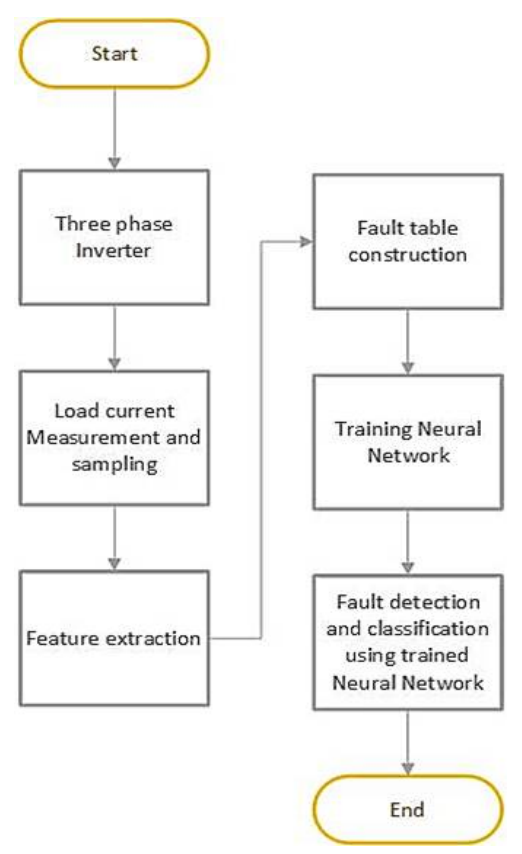

Figure 1. Flow of operation in the proposed method.

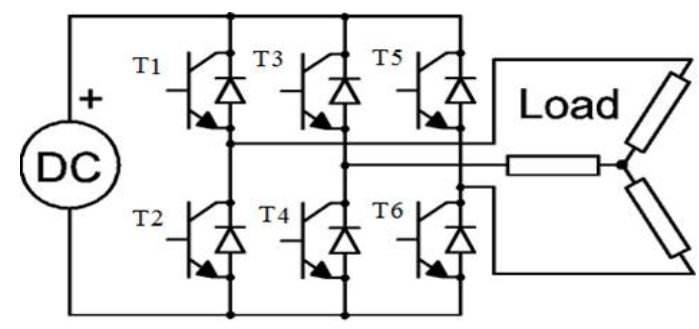

Figure 2. Three-phase inverter.

Most of the faults related to inverters are easy to detect and classify such as AC line faults, line to ground, phase to phase, open circuit or short circuit faults. But in case of gate switches fault, it is hard to classify faulty part of switching transistors. Therefore, an effective way of fault detection and classification in introduced in this paper. This technique detects and diagnose the fault with $100 \%$ accuracy. This process is conducted in different steps like measuring the load current, feature extraction process, fault table construction, training of neural network, fault detection and classification using the trained neural network. Flow chart in show in Figure 1.

\section{Fault Detection System Structure}

Three phase inverter with ' $\mathrm{Y}$ ' connected load is shown in Figure 2. T1-T6 are six gate transistors of inverter.

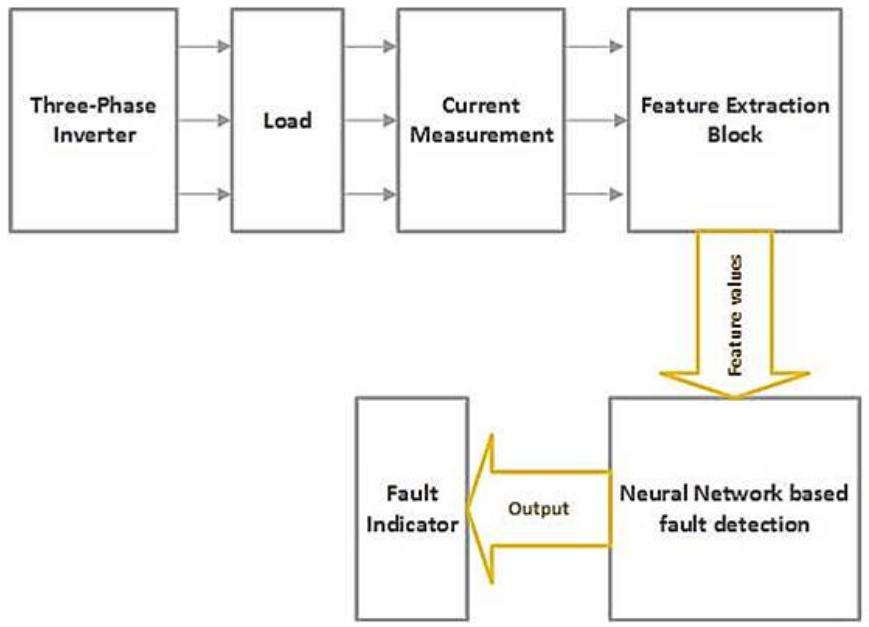

Figure 3. Proposed system block diagram.

Fault detection in three-phase inverter system is directly dependent on the output load current which is sensed by using sensors and sampled for processing. Later-on, an efficient feature extraction technique is used to extract the maximum possible effective features from the operating system. Afterwards, these features are calculated for various fault cases. A fault table is constructed, which consists of the feature vector values under different fault cases. This table is further used to train the neural network and this trained neural network is used for fault detection and diagnosis. Proposed system block diagram is shown in Figure 3.

\section{Feature Extraction Methodology}

Feature extraction is the key point of proposed fault detection and classification process. Better features will result a better performance and reliable system.

In this paper, comparatively new feature extraction technique is introduced. This technique considers output three phase current waveforms. In normal conditions, these current values create a donut like circle in three-dimensional space as shown in Figure 4. Each fault in system cause disturbance in three-phase current, which changes the radius of three-dimensional circle. Eq. (1) indicates the radius calculation of three-dimensional circle via three-phase current values.

$$
R^{2}=I_{a}^{2}+I_{b}^{2}+I_{c}^{2}
$$

In case of any fault in operating system, this three-dimensional circle changes its shape in unique way. These shapes are independent form each other with respect to their orientation or 


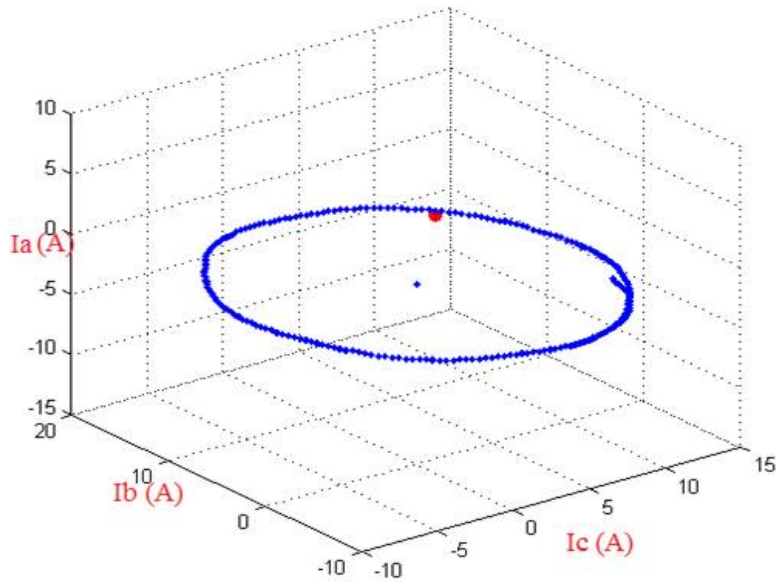

Figure 4. Current pattern 3D graph for system in normal mode.

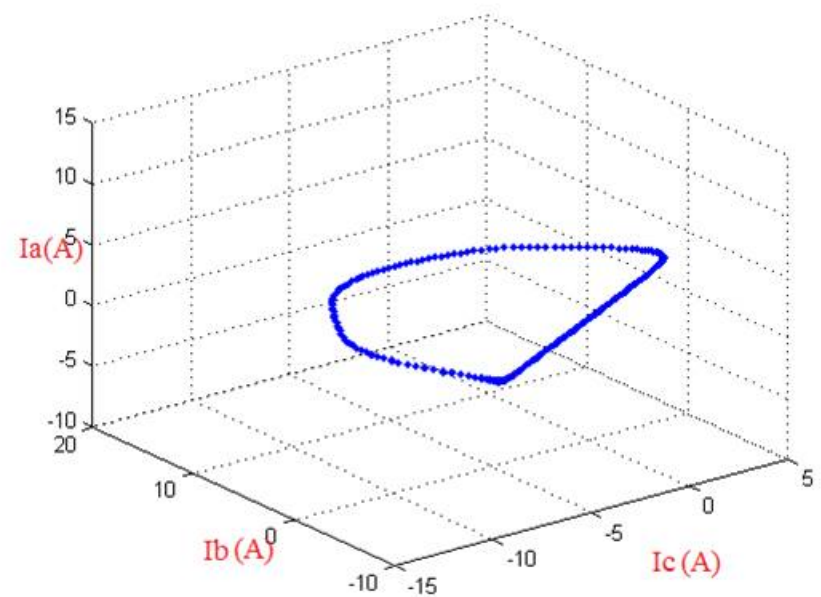

Figure 5. Current pattern 3D graph for system in single fault mode (T1).

structure for all faults. All these faults such as single, double and triple switch faults have their own independent shapes. T1 and T2 fault shapes are shown in Figures 5 and 6, respectively.

In case of two faults simultaneously across a single phase, current 3D graph is more or less same like a circle but with different orientation in three-dimensional space as shown in Figure 7.

In case of triple fault, a unique shape can be seen in Figure 8.

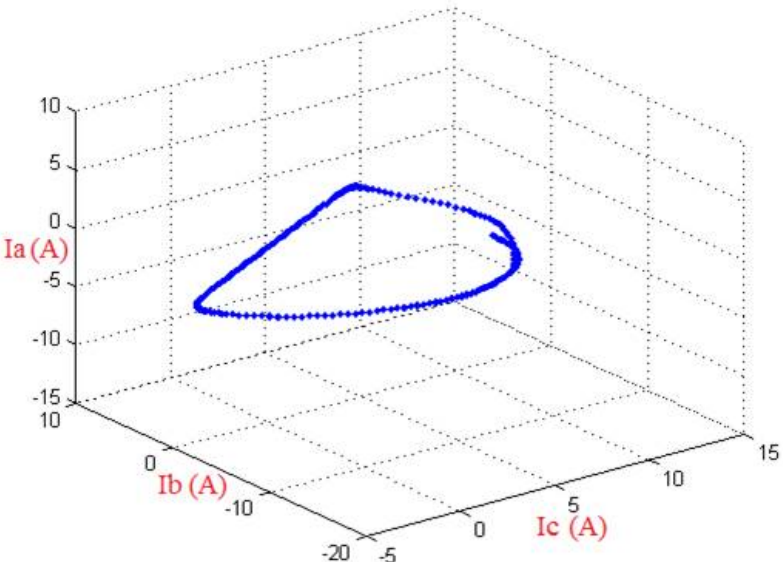

Figure 6. Current pattern 3D graph for system in single fault mode (T2).

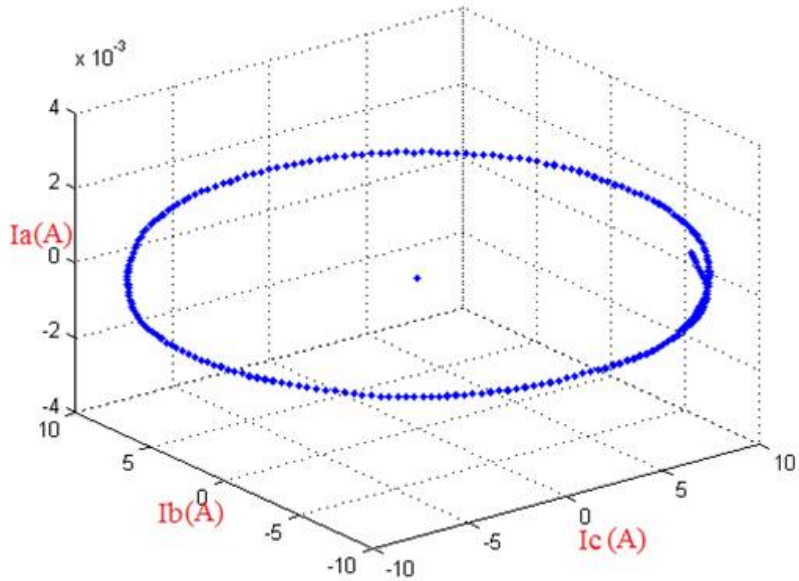

Figure 7. Current pattern 3D graph for system in double fault mode (T5 \& T6).

\subsection{Mean Current Values}

These different graphs indicate the variation in mean values of each current signal. Therefore, we get unique point in 3D plot of each mean value as $I_{a(\text { mean })}, I_{b(\text { mean })}$, and $I_{c(\text { mean })}$.

$$
\begin{aligned}
I_{a(\text { mean })} & =\sum I_{a} / N, \\
I_{b(\text { mean })} & =\sum I_{b} / N, \\
I_{c(\text { mean })} & =\sum I_{c} / N .
\end{aligned}
$$




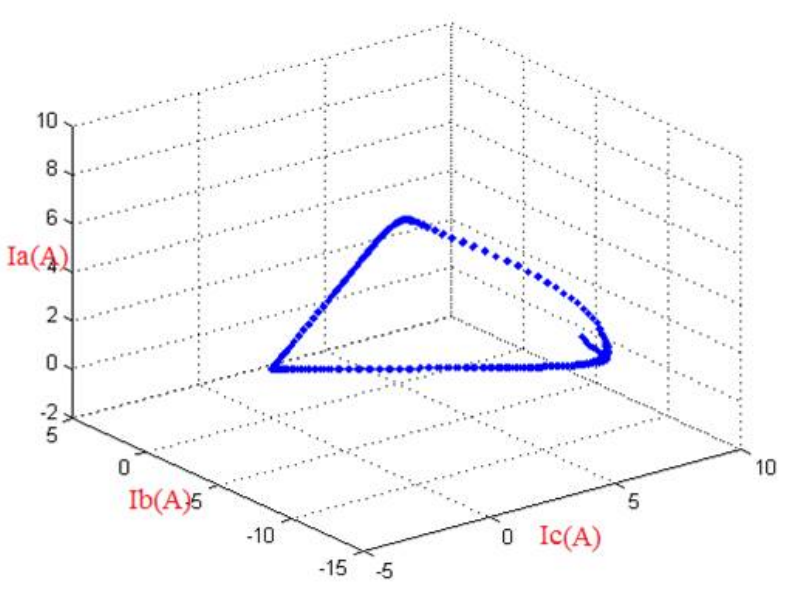

Figure 8. Current pattern 3D graph for system in triple fault mode (T2, T3 \& T6).

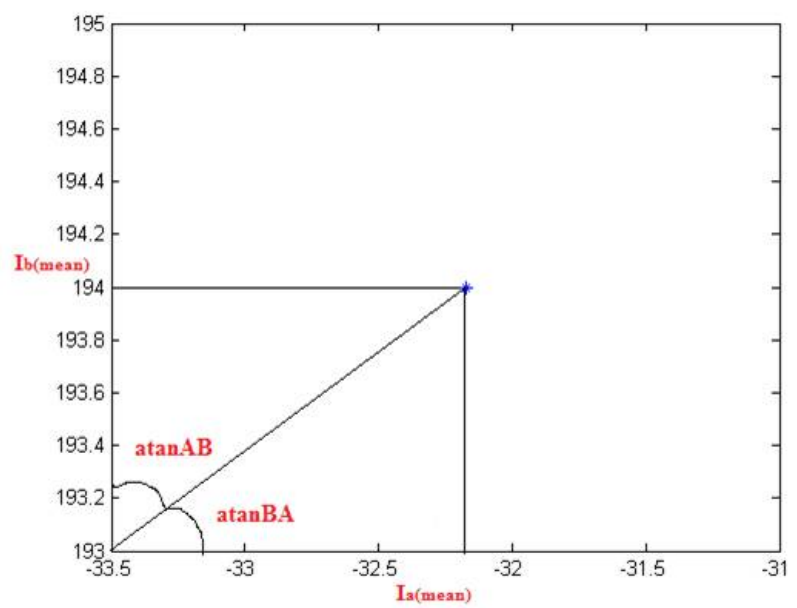

Figure 9. Angle measurement in two-dimensional space.

\subsection{Angle Calculation for Mean Points}

Next feature to be extracted is the angle of the each mean with respect to its axis. Angle to mean value gives us the exact location of that point in three-dimensional space.

Six angles for each point based on three mean values $\left(I_{a(\text { mean }}\right)$, $\left.I_{b(\text { mean })}, I_{c(\text { mean })}\right)$ are considered for specific fault or normal case. Following equations explain the angles calculation. Figure 9 describes these angles in two-dimensional space for better understanding.

$$
\begin{aligned}
& \operatorname{atanBA}=\tan ^{-1}\left(I_{b(\text { mean })} / I_{a(\text { mean })}\right), \\
& \operatorname{atanCA}=\tan ^{-1}\left(I_{c(\text { mean })} / I_{a(\text { mean })}\right),
\end{aligned}
$$

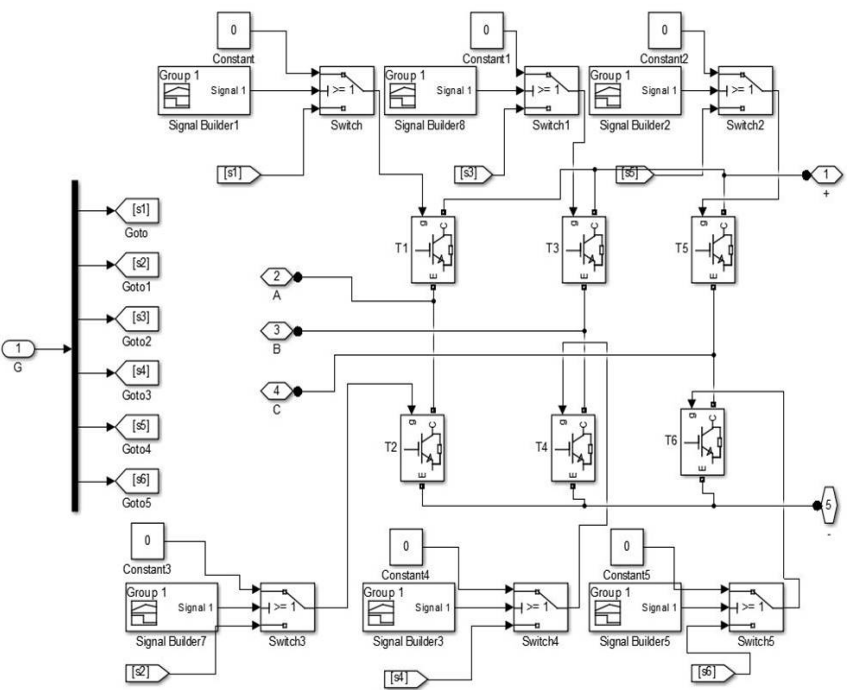

Figure 10. Simulink based three-phase inverter.

$$
\begin{aligned}
\operatorname{atan} \mathrm{AC} & =\tan ^{-1}\left(I_{a(\text { mean })} / I_{c(\text { mean })}\right), \\
\operatorname{atanBC} & =\tan ^{-1}\left(I_{b(\text { mean })} / I_{c(\text { mean })}\right), \\
\operatorname{atan} \mathrm{AB} & =\tan ^{-1}\left(I_{a(\text { mean })} / I_{b(\text { mean })}\right), \\
\operatorname{atanCB} & =\tan ^{-1}\left(I_{c(\text { mean })} / I_{b(\text { mean })}\right) .
\end{aligned}
$$

\section{Simulation Studies}

Matlab/Simulink programming environment is used to simulate and test the proposed algorithm. It enables us to design, measure and control any type of electrical, mechanical or electromechanical system.

This simulation based experiment is divided into following parts.

1) Three-phase inverter design

2) Feature extraction

3) Fault table based on extracted features

4) Neural network training

5) System testing and results

6) Comparison with previous feature extraction techniques

\subsection{Three-Phase Inverter Design}

A simple sinusoidal pulse width modulation (SPWM) threephase inverter is designed by using Simulink as show in Figure 10. SPWM is best technique to generate a sine wave at output. This PWM technique involves generation of a digital waveform. Duty cycle of the generated waveform can be modulated in such 
a way that average voltage waveform corresponds a pure sine wave [3]. In SPWM inverter, six sinusoidal PWM signals are generated to provide gate signals to six IGBT inverter switches with $120^{\circ}$ phase difference.

\subsection{Feature Extraction}

To apply the proposed feature extraction technique to simulation system, it is convenient to write it in mathematical language. Therefore, S-function builder in Matlab/Simulink is used to write a $\mathrm{C}$-code for feature extraction from three-phase load current. S-function builder is a helpful tool which allows to communicate the Matlab/Simulink graphical language with Clanguage. The C-code is written according to aforementioned equations (Section 3 ) and S-function builder converts this code in Simulink language. Featured data is computed under various fault conditions and fault table is constructed as shown in Table 1.

\subsection{Fault Table Based on Extracted Features}

The final part of feature extraction is to construct a fault table which includes the respective feature values for each fault case. These feature values must be carefully noted because these values are used for training the neural network in next steps. Fault table is shown in Table 1.

Matlab has its own neural network toolbox in which we can select the type of system, system input/output matrix for training. Collected data as shown in fault table is used to train the neural network. Neural network toolbox can generate different types of code after training is finished such as Simulink block diagram, Matlab function, etc. Matlab function for this trained system is generated and connected to simulation model via Matlab function block as shown in Figure 11.

\subsection{Neural Network Training}

Neural network is a system which is modeled on the human brain and nervous system. It needs to be trained by inputs and required outputs before using it in specific system. It consists of input layer, hidden layer and output layer. Weights of hidden nodes are calculated during the training process to provide the exact output in case of same or nearly equal input combinations. Generic representation on neural network is shown in Figure 12.

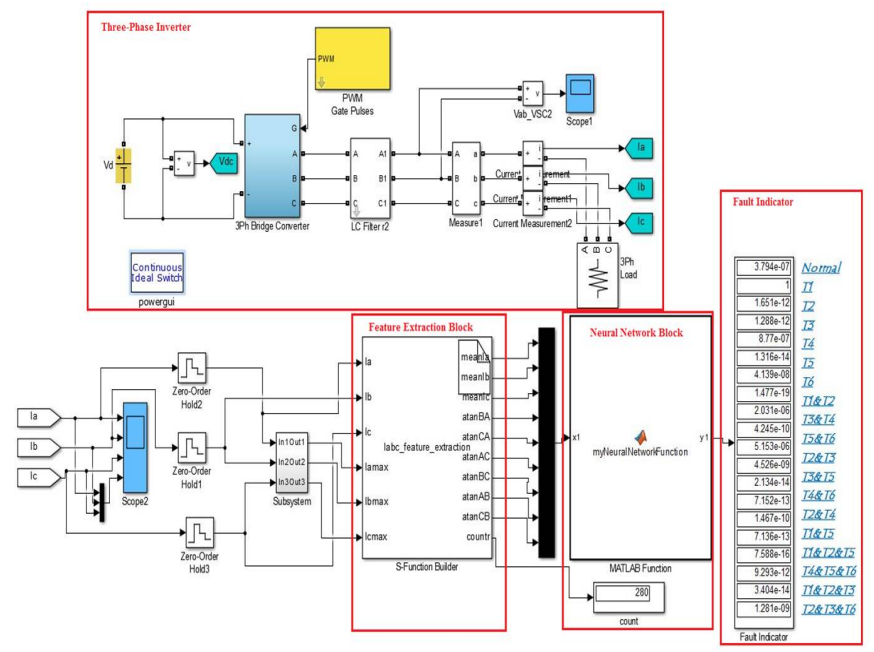

Figure 11. Architecture of neural network.

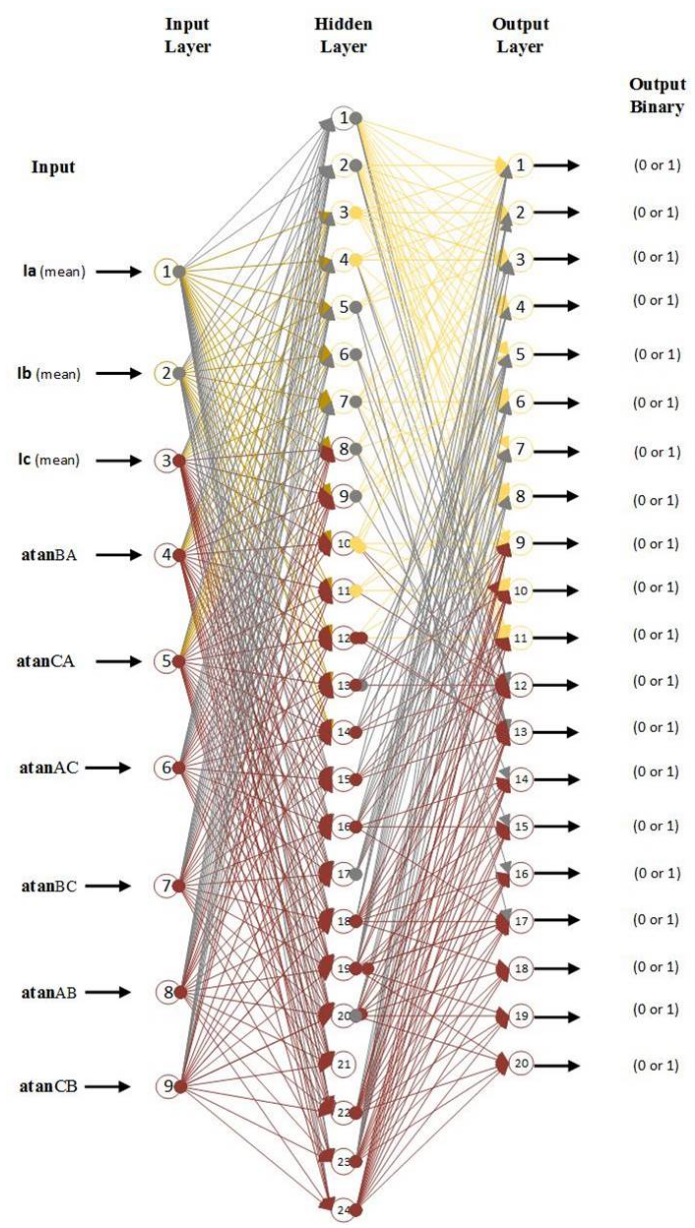

Figure 12. Matlab/Simulink based fault detection system.

\subsection{System Testing and Results}

Simulink based fault detection and monitoring system can be seen in Figure 11. All faults and normal condition can be 
Table 1. Fault table

\begin{tabular}{cccccccccc}
\hline Fault $\backslash$ Feature & $I_{a}($ mean $)$ & $I_{b}($ mean $)$ & $I_{c}($ mean $)$ & atanBA & atanCA & atanAC & atanBC & atanAB & atanCB \\
\hline Normal & 3.3 & 3.3 & 3.3 & 45 & 45 & 45 & 45 & 45 & 45 \\
T1 & -32 & 19.5 & 19.5 & 120 & 120 & 225 & 45 & 225 & 45 \\
T2 & 35.5 & -13.33 & -13.4 & 200 & 200 & 160 & 315 & 159 & 315 \\
T3 & 20 & -32.3 & 20 & 240 & 45 & 45 & 240 & 120 & 120 \\
T4 & -13.4 & 35.6 & -13.4 & 160 & 315 & 315 & 160 & 200 & 200 \\
T5 & 19.5 & 19.5 & -32.21 & 45 & 240 & 120 & 120 & 45 & 240 \\
T6 & -13.5 & -13.4 & 25.5 & 315 & 168 & 200 & 200 & 315 & 160 \\
T1\&T2 & 0 & 2.8 & 2.8 & 0 & 0 & 0 & 45 & 0 & 45 \\
\hline T3\&T4 & 2.8 & 0 & 2.8 & 0 & 45 & 45 & 0 & 0 & 0 \\
\hline T5\&T6 & 2.8 & 2.8 & 0 & 45 & 0 & 0 & 0 & 45 & 0 \\
\hline T2\&T3 & 41 & -38 & 2.8 & 225 & 2.8 & 87 & 266 & 138 & 93 \\
\hline T3\&T5 & 41 & 2.8 & -37.9 & 2.8 & 222 & 138 & 93 & 87.2 & 266.5 \\
\hline T4\&T6 & -43 & 24 & 24 & 119 & 119 & 240 & 45 & 240 & 45 \\
T2\&T4 & 24 & 24 & -43 & 45 & 240 & 119 & 119 & 45 & 240 \\
\hline T3\&T5 & 46 & -21 & -21 & 204 & 204 & 156 & 315 & 156 & 315 \\
\hline T1\&T5 & -21 & 46 & -21 & 156 & 315 & 315 & 156 & 204 & 204 \\
\hline T1\&T2\&T5 & 0 & 20 & -27 & 0 & 0 & 0 & 138 & 0 & 222 \\
\hline T4\&T5\&T6 & -27 & 30 & 0 & 138 & 0 & 0 & 0 & 222 & 0 \\
\hline T1\&T2\&T3 & 0 & 0 & 0 & 0 & 0 & 0 & 0 & 0 & 0 \\
\hline T2\&T3\&T6 & 24.37 & -43.7 & 24.9 & 240 & 45 & 45 & 240 & 119 & 119 \\
\hline
\end{tabular}
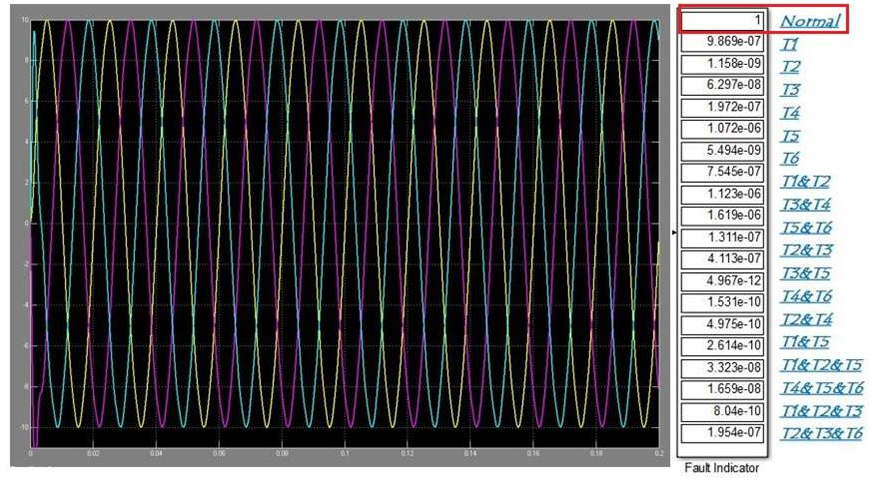

Figure 13. Normal case waveform and indication.

seen in fault indication block, corresponding fault bit turns to ' 1 ' in faulty case and rest of the values are nearly equal to zero. Output results of the fault detection system with their corresponding current waveforms under different fault cases are shown in following figures.

Normal case output is shown in Figure 13 in which perfect current waveform can be seen with the normal bit turned to ' 1 '.
All three waveforms for three-phase load current are identical in normal case. Disturbance, deformation or partial missing of the waveforms can be seen in rest of fault cases. Corresponding current signals for faulty switches will show the abnormal behavior in Figures 14-16.

Single Transistor fault (T1 fault) is shown in Figure 14. Three-phase current waveform is deformed because of fault and fault indicator is indicating it correctly (Note: All faults from $\mathrm{T} 1$ to $\mathrm{T} 6$ discussed here, refers to the Figure 2 switching combinations).

\subsection{Comparison with Previous Feature Extraction Tech- niques}

Various feature extraction techniques were introduced in past to detect and diagnose the faults in three-phase inverter systems such as discrete wavelet transform (DWT) \& support vector machine (SVM), dq0 transform, principal component analysis (PCA) and current mean value [4], etc. Comparison of proposed method with these previous methods is shown in Table 2. Previous techniques such as DWT \& SVM and PCA con- 

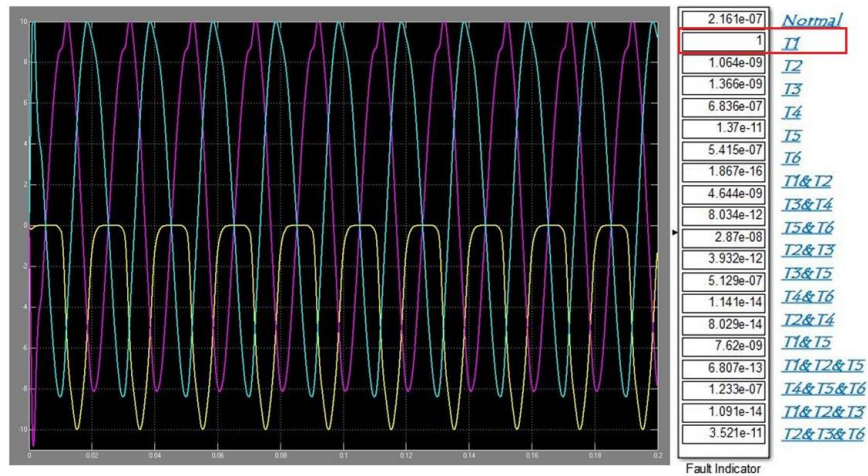

Figure 14. T1 switching fault case waveform and indication.
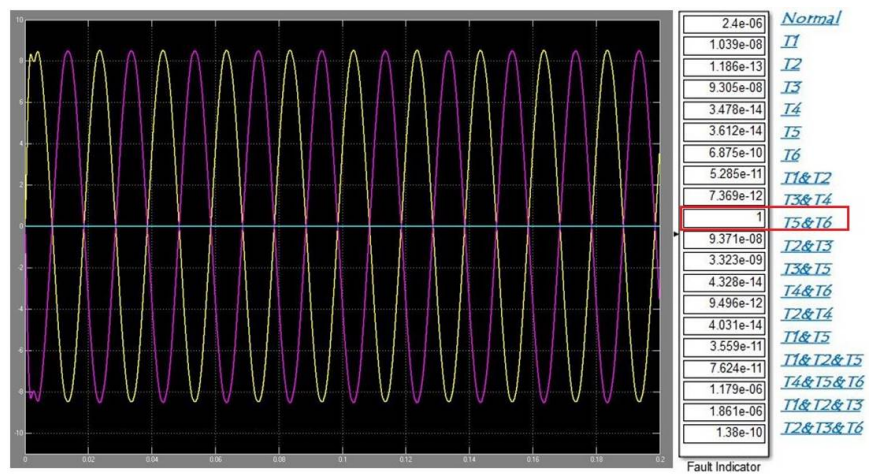

Figure 15. T5\&T6 switching fault case waveform and indication.
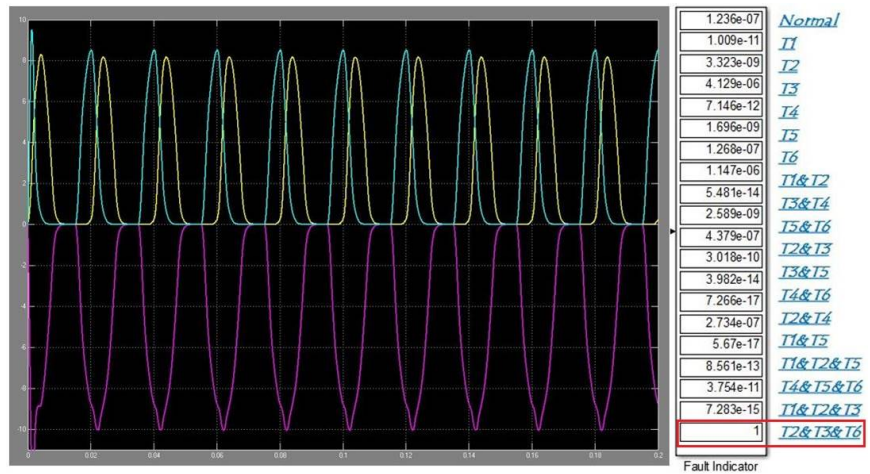

Figure 16. T2\&T3\&T6 switching fault case waveform and indication.

sists of complex mathematical computations which is bulky and increases the response time. This effects the efficiency due to time delay in fault detection and diagnosis process. The other techniques with less computation time such as dq0 transformation or entropy technique lacks in the quality of extracted features.

These inadequate features cause low efficiency and decrease in accuracy in diagnosis process.
Proposed technique consists of simple mathematical calculations which dont take much time to be executed. Threedimensional space feature extraction provides nine feature vectors which are sufficient to detect and diagnose all type of faults with high accuracy and minimum time span (single current cycle).

\section{Conclusion}

After successful implementation and testing of the proposed technique, it is concluded that proposed fault detection and diagnosis results are exceptional. Also the proposed feature extraction algorithm is simple as it doesnt require any complex mathematical calculations in comparison to previous techniques. Simplicity of the system increases response time, thats why proposed system can detect the faults with high speed and accuracy. This system can detect and diagnose single or multiple faults in single current cycle with $100 \%$ accuracy. In future work, the same technique can be used to analyze the faults in three-phase motors, generators, energy management systems, etc.

\section{Conflict of Interest}

No potential conflict of interest relevant to this article was reported.

\section{Acknowledgements}

This work was supported by Business for Academic-Industrial Cooperative establishments funded Korea Small and Medium Business Administration in 2015 (No. C0268141).

\section{References}

[1] D. E. Kim and D. C. Lee, "Fault diagnosis of threephase PWM inverters using wavelet and SVM," Journal of Power Electronics, vol. 9, no. 3, pp. 377-385, 2009. http://dx.doi.org/10.1109/ISIE.2008.4676998

[2] F. Kadri, S. Drid, F. Djeffal, and L. Chrifi-Alaoui, "Neural classification method in fault detection and diagnosis for voltage source inverter in variable speed drive with induction motor," in Proceedings of 2013 8th International Conference and Exhibition on Ecological Vehicles and Renewable Energies, Monaco, 2013. http: //dx.doi.org/10.1109/EVER.2013.6521549 
Table 2. Comparison table

\begin{tabular}{|c|c|c|c|}
\hline $\begin{array}{l}\text { Feature extraction } \\
\text { methods }\end{array}$ & Accuracy & $\begin{array}{l}\text { Response } \\
\text { speed }\end{array}$ & Comments \\
\hline $\begin{array}{l}\text { PCA \& current } \\
\text { mean value }\end{array}$ & Low & High & $\begin{array}{l}\text { - Low number of feature vectors. } \\
\text { - Complex PCA computations. (only detect single faults) }\end{array}$ \\
\hline DWY \& SVM & High & Low & - Large mathematical computation time for DWT and SVM (slow response). \\
\hline $\begin{array}{l}\text { DQ0 } \\
\text { transformation }\end{array}$ & Medium & High & - Confound features under simultaneous faults. \\
\hline $\begin{array}{l}\text { Three-phase } \\
\text { feature extraction }\end{array}$ & High & High & $\begin{array}{l}\text { - Low computation time. } \\
\text { - Explicit and independent features for all fault types (single, double, triple). }\end{array}$ \\
\hline
\end{tabular}

DWY:

[3] S. Phogat, "Analysis of single-phase SPWM inverter," International Journal of Science and Research, vol. 3, no. 8, pp. 1793-1798, 2014.

[4] J. F. Martins, V. F. Pires, C. Lima, and A. J. Pires, "Fault detection and diagnosis of grid-connected power inverters using PCA and current mean value," in Proceedings of 38th Annual Conference on IEEE Industrial Electronics Society (IECON2012), Montreal, Canada, 2012. http://dx. doi.org/10.1109/IECON.2012.6388972

[5] M. Ubale, R. B. Dhumale, V. V. Dixit, and S. D. Lokhande, "Method of open switch fault detection in three phase inverter using artificial neural network," International Journal for Research in Science \& Advanced Technologies, vol. 3, no. 3, pp. 78-82, 2013.

[6] V. Gomathy and S. Selvaperumal, "Fault detection and classification with optimization techniques for a threephase single-inverter circuit," Journal of Power Electronics, vol. 16, no. 3, pp. 1097-1109, 2016. http://dx.doi.org/ 10.6113/JPE.2016.16.3.1097

[7] W. S. Im, J. S. Kim, J. M. Kim, D. C. Lee, and K. B. Lee, "Diagnosis methods for IGBT open switch fault applied to 3-phase AC/DC PWM converter," Journal of Power Electronics, vol. 12, no. 1, pp. 120-127, 2012. http://dx. doi.org/10.6113/JPE.2012.12.1.120

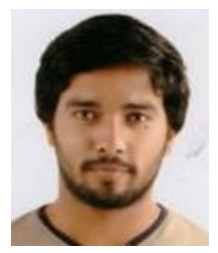

Muhammad Talha received the B.S. degree in Electrical Engineering from the University of Faisalabad in 2012. Finished M.S. in Control System Engineering from Kunsan National University in 2015. Current Ph.D. student in Kunsan National University. His research interests include Renewable energy systems, Power converters and Fuzzy Logic.

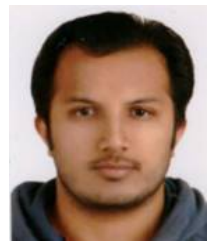

Furqan Asghar received the B.S. degree in Electrical Engineering from The University of Faisalabad in 2012. Finished M.S. in Control System Engineering from Kunsan $\mathrm{Na}-$ tional University in 2015. Current Ph.D. student in Kunsan National University. His research interests include Renewable energy systems, Artificial Neural Network and Fuzzy Logic.

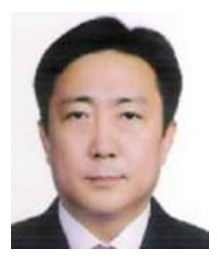

Sung Ho Kim received the B.S. degree in Electrical Engineering from Korea University in 1984. Finished M.S. from Korea University in 1986. Completed Ph.D. from Korea University in 1991. Completed POST-DOC from Hiroshima University (Japan). Current, professor at Kunsan National University. His research interests include Wind Turbine system, sensor networks, Neural Network and Fuzzy Logic, Intelligent control systems. 